\title{
Investigating the relationship between spiritual intelligence and post-traumatic stress syndrome in health care workers in Covide19 centers
}

Somayeh Rezaie ( $\sim$ s.rezaie@shmu.ac.ir)

Shahroud University of Medical Sciences

Salman Daliri

Shahroud University of Medical Sciences

Hossein Sheibani

Imam Hossein Hospital, Shahroud University of Medical Sciences

Seyed Shahrokh Aghayan

Shahroud University of Medical Sciences

Nasrin Fadaeaghdam

Shahroud University of Medical Sciences

\section{Zahra Banar}

Shahroud University of Medical Sciences

\section{Samaneh Sayad}

Shahroud University of Medical Sciences

\section{Research Article}

Keywords: Covide-19, PTSS, Spiritual Intelligence, Health Care Workers

Posted Date: March 7th, 2022

DOI: https://doi.org/10.21203/rs.3.rs-1328014/v1

License: (9) This work is licensed under a Creative Commons Attribution 4.0 International License. Read Full License 


\section{Abstract}

Background: In December 2019, an infectious disease caused by the new coronavirus (Covid-19) started in Wuhan, China and spread rapidly around the world. Due to the fact that this pandemic, in addition to causing general health concerns in the world, has caused numerous psychological complications.

Objectives: this study was conducted to investigate the relationship between spiritual intelligence and the level of post-traumatic stress syndrome in Health care workers in Iran.

Method: This descriptive-analytical study was performed on 201 health care workers in covid19 centers in Shahroud and Miami in Semnan province. The statistical population included the personnel of different categories of the hospital and was selected by stratified sampling method. Online Demographic questionnaire, IES-R questionnaire for PTSS (POST TRAUMATIC STRESS SYNDROME) and online spiritual intelligence questionnaire were used to collect information.

Results: The mean score PTSS $33.97 \pm 17.57$ and the three subscales of avoidance, intrusion and hyperarousal were $13.39 \pm 6.39,10.27 \pm 6.27$ and $10.04 \pm 27$, respectively. Also, the mean score of spiritual intelligence was $124.90 \pm 16.99$. Pearson correlation coefficient showed a negative relationship between spiritual intelligence and PTSS $(-0.25)$, avoidance $(-0.16)$, intrusion $(-0.2)$ and hyperarousal $(-0.3)$, and with increasing spiritual intelligence, people experienced fewer PTSS.

Conclusion: Given the high prevalence of mental health disorders and the high rate of PTSS in covid19 pandemic, and considering the relationship between spiritual intelligence and the extent of PTSS symptoms. Based on the findings of this study, the use of strategies such education about spiritual intelligence can be used as a way to better adapt and reducing the complications of this crisis.

\section{Background}

On December 31, 2019, the World Health Organization (WHO) reported several unusual cases of pneumonia in Wuhan, China, caused by a new subtype coronavirus called Acute Respiratory Syndrome due to coronavirus type 2 (SARS-COV2)(1). The disease spread rapidly from China to other countries. On February 11, 2020, WHO declared the 2019-nCoV epidemic a coronavirus (COVID-19). The International Committee for the Classification of Viruses later renamed it SARS-CoV-2 Acute Respiratory Syndrome (2). On January 30, 2020, the WHO declared the outbreak of COVID-19 as the sixth public health emergency (3). According to the latest report of the WHO, as of January 1, 2021, more than 82 million cases of the disease have been reported in 218 countries, and the prevalence of new cases and deaths due to it is increasing (4).

The high prevalence of this disease has not only caused a worldwide health concern but also leads to extraordinary mental and psychological problems that can be attributed to such things as depression, anxiety, insomnia, attention disorder, irritability, fatigue and especially Post-traumatic stress syndrome noted that if not identified and treated, it can lead to chronic diseases (5). 
During the pandemic period, health professionals are one of the most affected groups because they have to experience one of the paradoxes of this epidemic while people in the community stay at home and maintain social distance. They are forced to stay at work. And have a close relationship with patients, and on the other hand, various deficiencies such as lack of personal protective equipment and unknown disease make them among the vulnerable groups, and in addition to physical health, their mental health is also affected $(6,7)$.

Post-traumatic stress disorder (PTSD) is a mental disorder that can develop after exposure to extremely threatening or horrific events. Its main characteristics are disturbing memories, avoidant behaviors, and a feeling of constant threat to alertness or excessive alertness. PTSD is a stress-related psychological problem caused by someone who has experienced or witnessed a life-threatening traumatic event, which has placed a heavy burden on individuals and society (8). Exposure to traumatic events is the immediate cause of PTSD and is essential in diagnosing related symptoms $(9,10)$.

Post-traumatic stress Syndrome (PTSS) is also an acute traumatic stress that can have lasting and chronic effects on mental health $(11,12)$. Despite all the efforts of the WHO and senior public health officials around the world to contain the outbreak of COVID-19, however, the disease has caused stress in the entire population of the world. The WHO Department of Mental Health, while providing standard solutions, Appropriate and practical interventions for mental and well-being of all groups involved in this disease are considered a necessity (4). Research on mental health of health care workers involved in the outbreak of SARS showed that about $10 \%$ of the samples Have shown high symptoms of PTSD (13). In addition, a study of long-term psychological effects among SARS survivors found that PTSD was the most common long-term mental disorder (14). Another study found that approximately $4.4 \%$ of health care workers in China showed high levels of PTSD during the H1N1 epidemic in 2019 (15). As a result, early detection and intervention for PTSD deserves special attention in the prevalence of life-threatening medical illnesses(14).

Spiritual intelligence is one of the new concepts of human intelligence and includes a kind of compromise and problem-solving behavior (16) and it can be defined as paying attention to spirituality in solving problems and problems of life and valuing human life (17). Spiritual intelligence can be classified into four categories: critical ontology thinking, creating meaning in life, transcendent consciousness, and expanding the state of consciousness $(18,19)$. This intelligence gives the person an overview of all life events and experiences and enables the person to reinterpret their events. According to many studies, spiritual intelligence and attention to spirituality can be effective in reducing stress and anxiety, wellbeing, increasing quality and meaning in life, so that the higher the spiritual intelligence, the lower the level of stress and anxiety and They will experience a better quality of life $(16,20)$. Since the fear of change is due to the mind of people and not the environment around him, so spiritual intelligence helps people to fight the fear of change while controlling the unpleasant feelings in their being (20).

At the time of the outbreak of life-threatening physical illnesses, early detection of PTSS and methods and strategies to prevent and reduce it need special attention. Given that hundreds of thousands of 
health care workers work at the forefront of Covid-19, their mental health is essential to control the pandemic and it should be considered by health system policymakers.

\section{Objectives}

The present study aims to investigate the relationship between spiritual intelligence and PTSS Covid-19 treatment has been performed to take steps to improve the health of these people and ultimately improve the health of the community.

\section{Materials And Methods}

This descriptive-analytical study was performed on 201 health care workers working in covid-19 treatment centers in Shahroud and Miami in Semnan province (Iran). After obtaining the code of ethics from the ethics committee of Shahroud University of Medical Sciences, data were collected in the hospitals of covid- 19 centers.

Inclusion criteria included willingness to participate in the study, employment during the Covid-19 pandemic period in the hospital, History of self-reported mental illness and exclusion criteria included incomplete completion of questionnaires.

The sampling method was stratified. At first, the characteristic of the employees working in the hospitals were received. Then, the number of samples was determined based on occupational groups and simple random sampling was performed among them. Initially, due to Covid-19 epidemic, questionnaires were prepared electronically and the relevant link was sent to the contact numbers of people eligible to participate in the project. In the electronic questionnaire, after stating the purpose of the project, the first question was satisfaction. They were not satisfied to participate in the project and chose the no option, the questionnaire questions were not shown to them and they were excluded from the study. One week after sending the questionnaire link, the questionnaires were first checked for the ratio of participation of the target groups, and if the ratio of participation of the target groups was less than the percentage set according, questionnaire for alternative employees sent.

The questionnaires used in this study included demographic information questionnaire, The Impact of Event Scale - Revised questionnaire (IES-R) and spiritual intelligence questionnaire. The Impact Event Scale (IES-R) was used to assess the level of stress experienced by individuals. This questionnaire had 22 questions, of which 5 questions were added to the original version (IES) in order to include the DSM V criteria. Self-report tools are designed to assess the extent of PTSS. This questionnaire is not for diagnosing PTSS but is a suitable tool for measuring the mental response to a stressful event in adults and can be used in recent stressful situations (12). In this questionnaire, the dimensions of mental helplessness in the face of specific events, including avoidance, intrusion and hyperarousal, are evaluated and are usually used to assess PTSS. In this tool, a score above 24 indicates PTSS, and the higher the score, the greater the concern about PTSS $(21,22)$. The Spiritual Intelligence Questionnaire 
consists of 29 questions that consist of two factors. The first factor was called with 12 questions (understanding and connection with the source of existence) and the second factor with 17 questions (spiritual life with an inner core). The minimum score will be 29 and the maximum 145. Score between 29 and 58 low, 58 and 87 average and Score higher than 87 is high spiritual intelligence (23).

\subsection{Statistical Analysis}

Statistical analysis of data using descriptive statistical tests including estimation of mean and frequency and to examine the relationship between variables Chi-square, independent sample t test and Pearson correlation coefficient tests by SPSS software version 22 was used. Significance level was considered 0.05 .

\section{Results}

Participants included 201 personnel from various groups working in the hospital. The mean age of participants was $34.02 \pm 7.6$ years. $57.6 \%$ female, $76.1 \%$ married, $45.8 \%$ nurses, $40.3 \%$ bachelor, $6.5 \%$ Underlying disease and $13 \%$ History of Covid-19 disease, respectively (Table 1 ). 
Table 1

Demographic characteristic of participant

\begin{tabular}{|ll|}
\hline Variable & Frequency (\%) \\
\hline Gender & \\
\hline Male & $85(42.4)$ \\
\hline Female & $116(57.6)$ \\
\hline Marital status & \\
\hline Married & $153(76.1)$ \\
\hline Single & $45(22.4)$ \\
\hline Divorced & $3(1.5)$ \\
\hline Job & \\
\hline physician & $1(0.5)$ \\
\hline Official & $65(36.3)$ \\
\hline Nurse & $99(45.8)$ \\
\hline EMS & $3(1.5)$ \\
\hline Security & $33(15.9)$ \\
\hline Education & \\
\hline Associate Degree & $51(25.4)$ \\
\hline Bachelor & $81(40.3)$ \\
\hline Master & $63(31.3)$ \\
\hline physician or PhD & $6(2.5)$ \\
\hline Number of Children & $105(52.3)$ \\
\hline 1 & $22(10.1)$ \\
\hline 2 & $63(31.4)$ \\
\hline $2<$ & $56(28)$ \\
\hline work experience (year) & \\
\hline $5>$ & \\
\hline $11-20$ & \\
\hline $20<$ & \\
\hline
\end{tabular}




\begin{tabular}{|ll|}
\hline Variable & Frequency (\%) \\
\hline Underlying disease & $14(6.5)$ \\
\hline Yes & $187(93.5)$ \\
\hline No & \\
\hline Underlying disease in first-degree relatives & $78(38.7)$ \\
\hline Yes & $123(61.3)$ \\
\hline No & \\
\hline History of Covid-19 disease & $25(13)$ \\
\hline Yes & $176(87)$ \\
\hline No & \\
\hline Access to personal protective equipment & $17(8.3)$ \\
\hline weak & $64(31.9)$ \\
\hline Moderate & $69(34.4)$ \\
\hline Mild & $39(19.4)$ \\
\hline High & $12(6)$ \\
\hline Very high & \\
\hline
\end{tabular}

The mean score PTSS obtained in this study was $33.97 \pm 17.57$. The three subscales of avoidance, intrusion and hyperarousal were also examined separately. In the Subscales of avoidance, intrusion and hyperarousal the mean score was $13.39 \pm 6.39,10.27 \pm 6.27$ and $10.04 \pm 27$, respectively.

The results showed that there was no significant relationship between PTSS score and age, gender, work experience, Past Medical History (such as diabetes mellitus hypertension, cardiovascular disorder) and access to personal protective equipment $(p>0.05)$.

The mean score of spiritual intelligence were $124.90 \pm 16.99$, respectively, based on the cut points, $3.6 \%$ had moderate spiritual intelligence and $96.4 \%$ high spiritual intelligence. To investigate the relationship between spiritual intelligence and demographic characteristic, the results showed that there was no significant relationship between spiritual intelligence score with age, gender, and work experience, underlying disease and access to personal protective equipment $(p>0.05)$. Also, there was no significant relationship between PTSS with demographic characteristic $(p>0.05)$ (Table 2$)$. 
Table 2

The relationship between spiritual intelligence and PTSS with demographic characteristic

\begin{tabular}{|c|c|c|c|c|c|c|}
\hline \multirow[t]{3}{*}{ Variable } & \multicolumn{3}{|c|}{ PTSS (score) } & \multicolumn{3}{|c|}{ Spiritual Intelligence (score) } \\
\hline & \multirow{2}{*}{$\begin{array}{l}24> \\
\text { n(\%) }\end{array}$} & \multirow{2}{*}{$\begin{array}{l}24 \leq \\
n(\%)\end{array}$} & \multirow[t]{2}{*}{$\begin{array}{l}\mathrm{P} \\
\text { Value }\end{array}$} & \multirow{2}{*}{$\begin{array}{l}\text { Mild (58- } \\
87) \\
n(\%)\end{array}$} & \multirow{2}{*}{$\begin{array}{l}\text { High } \\
(87<) \\
n(\%)\end{array}$} & \multirow[t]{2}{*}{$\begin{array}{l}\mathrm{P} \\
\text { Value }\end{array}$} \\
\hline & & & & & & \\
\hline \multicolumn{7}{|l|}{ Gender } \\
\hline Male & $28(45)$ & $57(40)$ & \multirow[t]{2}{*}{0.84} & $3(42.9)$ & $\begin{array}{l}82 \\
(42.2)\end{array}$ & \multirow[t]{2}{*}{0.52} \\
\hline Female & $34(55)$ & $82(60)$ & & $4(57.1)$ & $\begin{array}{l}112 \\
(57.8)\end{array}$ & \\
\hline \multicolumn{7}{|l|}{ Age } \\
\hline $30>$ & $19(30)$ & $46(31)$ & \multirow[t]{2}{*}{0.21} & $3(42.9)$ & $\begin{array}{l}62 \\
(31.8)\end{array}$ & \multirow[t]{2}{*}{0.16} \\
\hline $30<$ & $41(70)$ & $96(69)$ & & $4(57.1)$ & $\begin{array}{l}133 \\
(68.2)\end{array}$ & \\
\hline \multicolumn{7}{|l|}{ Education level } \\
\hline Associate Degree & $\begin{array}{l}18 \\
(28.5)\end{array}$ & $33(24)$ & \multirow[t]{4}{*}{0.27} & $3(37.5)$ & $\begin{array}{l}48 \\
(24.9)\end{array}$ & \multirow[t]{4}{*}{0.56} \\
\hline Bachelor & $\begin{array}{l}20 \\
(31.5)\end{array}$ & $61(45)$ & & $1(12.5)$ & $\begin{array}{l}80 \\
(41.5)\end{array}$ & \\
\hline Master & $23(37)$ & $40(29)$ & & $4(50)$ & $\begin{array}{l}59 \\
(30.6)\end{array}$ & \\
\hline physician or PhD & $2(3)$ & $4(2)$ & & $0(0)$ & $6(3)$ & \\
\hline \multicolumn{7}{|l|}{ Marital status } \\
\hline Married & $50(79)$ & $\begin{array}{l}103 \\
(75)\end{array}$ & \multirow[t]{3}{*}{0.25} & $8(100)$ & $\begin{array}{l}145 \\
(75.1)\end{array}$ & \multirow[t]{3}{*}{0.05} \\
\hline Single & $12(20)$ & $33(23)$ & & $0(0)$ & $\begin{array}{l}45 \\
(23.3)\end{array}$ & \\
\hline Divorced & $1(1)$ & $2(2)$ & & $0(0)$ & $3(1.6)$ & \\
\hline \multicolumn{7}{|l|}{ Job } \\
\hline physician & $0(0)$ & $1(0.5)$ & \multirow[t]{3}{*}{0.4} & $0(0)$ & $1(0.5)$ & \multirow[t]{3}{*}{0.1} \\
\hline Official & $\begin{array}{l}22 \\
(35.5)\end{array}$ & $43(31)$ & & $4(50)$ & $\begin{array}{l}61 \\
(31.6)\end{array}$ & \\
\hline Nurse & $26(42)$ & $\begin{array}{l}73 \\
(52.5)\end{array}$ & & $4(50)$ & $\begin{array}{l}95 \\
(49.2)\end{array}$ & \\
\hline
\end{tabular}




\begin{tabular}{|c|c|c|c|c|c|c|}
\hline \multirow[t]{4}{*}{ Variable } & \multicolumn{3}{|c|}{ PTSS (score) } & \multicolumn{3}{|c|}{ Spiritual Intelligence (score) } \\
\hline & $24>$ & $24 \leq$ & \multirow{3}{*}{ Value } & $\underset{87)}{\text { Mild (58- }}$ & High & \multirow{3}{*}{$\stackrel{P}{\text { Value }}$} \\
\hline & \multirow{2}{*}{$n(\%)$} & \multirow[t]{2}{*}{$n(\%)$} & & & & \\
\hline & & & & $n(\%)$ & $n(\%)$ & \\
\hline EMS & $1(1.5)$ & $2(1.5)$ & & $0(0)$ & $3(1.5)$ & \\
\hline Security & $13(21)$ & $\begin{array}{l}20 \\
(14.5)\end{array}$ & & $0(0)$ & $\begin{array}{l}33 \\
(17.2)\end{array}$ & \\
\hline \multicolumn{7}{|c|}{ Number of Children } \\
\hline 1 & $\begin{array}{l}25 \\
(38.5)\end{array}$ & $\begin{array}{l}62 \\
(45.6)\end{array}$ & \multirow[t]{3}{*}{0.29} & $3(43)$ & $\begin{array}{l}84 \\
(43.3)\end{array}$ & \multirow[t]{3}{*}{0.19} \\
\hline 2 & $\begin{array}{l}22 \\
(33.8)\end{array}$ & $\begin{array}{l}36 \\
(26.5)\end{array}$ & & $0(0)$ & $\begin{array}{l}58 \\
(29.9)\end{array}$ & \\
\hline $2<$ & $\begin{array}{l}18 \\
(27.7)\end{array}$ & $\begin{array}{l}38 \\
(27.9)\end{array}$ & & $4(57)$ & $\begin{array}{l}52 \\
(26.8)\end{array}$ & \\
\hline \multicolumn{7}{|c|}{ work experience (year) } \\
\hline $5>$ & $32(51)$ & $73(53)$ & \multirow[t]{4}{*}{0.32} & $5(71.5)$ & $\begin{array}{l}100 \\
(51.5)\end{array}$ & \multirow[t]{4}{*}{0.001} \\
\hline $5-10$ & $8(13)$ & $14(10)$ & & $0(0)$ & $\begin{array}{l}22 \\
(11.3)\end{array}$ & \\
\hline $11-20$ & $20(32)$ & $43(32)$ & & $2(28.5)$ & $\begin{array}{l}61 \\
(31.5)\end{array}$ & \\
\hline $20<$ & $3(4)$ & $8(5)$ & & $0(0)$ & $11(5.7)$ & \\
\hline \multicolumn{7}{|c|}{ Underlying disease } \\
\hline Yes & $6(9)$ & $8(5)$ & \multirow[t]{2}{*}{0.71} & $0(0)$ & $14(7.6)$ & \multirow[t]{2}{*}{0.6} \\
\hline No & $57(91)$ & $\begin{array}{l}130 \\
(95)\end{array}$ & & $18(100)$ & $\begin{array}{l}169 \\
(92.4)\end{array}$ & \\
\hline \multicolumn{7}{|c|}{$\begin{array}{l}\text { Underlying disease in first-degree } \\
\text { relatives }\end{array}$} \\
\hline Yes & $27(43)$ & $51(37)$ & \multirow[t]{2}{*}{0.5} & $0(0)$ & $\begin{array}{l}78 \\
(40.4)\end{array}$ & \multirow[t]{2}{*}{0.04} \\
\hline No & $36(57)$ & $87(63)$ & & $8(100)$ & $\begin{array}{l}115 \\
(59.6)\end{array}$ & \\
\hline \multicolumn{7}{|c|}{ History of Covid-19 disease } \\
\hline Yes & $7(12)$ & $18(13)$ & 0.24 & $0(0)$ & $\begin{array}{l}25 \\
(12.8)\end{array}$ & 0.56 \\
\hline
\end{tabular}




\begin{tabular}{|c|c|c|c|c|c|c|}
\hline \multirow[t]{3}{*}{ Variable } & \multicolumn{3}{|c|}{ PTSS (score) } & \multicolumn{3}{|c|}{ Spiritual Intelligence (score) } \\
\hline & \multirow{2}{*}{$\begin{array}{l}24> \\
n(\%)\end{array}$} & \multirow{2}{*}{$\begin{array}{l}24 \leq \\
n(\%)\end{array}$} & \multirow[t]{2}{*}{$\begin{array}{l}\mathrm{P} \\
\text { Value }\end{array}$} & \multirow{2}{*}{$\begin{array}{l}\text { Mild (58- } \\
87) \\
n(\%)\end{array}$} & \multirow{2}{*}{$\begin{array}{l}\text { High } \\
(87<) \\
n(\%)\end{array}$} & \multirow[t]{2}{*}{$\begin{array}{l}\mathrm{P} \\
\text { Value }\end{array}$} \\
\hline & & & & & & \\
\hline No & $57(88)$ & $\begin{array}{l}119 \\
(87)\end{array}$ & & $6(100)$ & $\begin{array}{l}170 \\
(87.2)\end{array}$ & \\
\hline \multicolumn{7}{|c|}{$\begin{array}{l}\text { Access to personal protective } \\
\text { equipment }\end{array}$} \\
\hline weak & $4(6.3)$ & $\begin{array}{l}13 \\
(9.5)\end{array}$ & 0.1 & $0(0)$ & $17(8.8)$ & 0.1 \\
\hline Moderate & $\begin{array}{l}16 \\
(25.5)\end{array}$ & $\begin{array}{l}48 \\
(34.8)\end{array}$ & & $5(71.4)$ & $\begin{array}{l}59 \\
(30.5)\end{array}$ & \\
\hline Mild & $\begin{array}{l}25 \\
(39.7)\end{array}$ & $\begin{array}{l}44 \\
(31.9)\end{array}$ & & $0(0)$ & $\begin{array}{l}69 \\
(35.6)\end{array}$ & \\
\hline High & $\begin{array}{l}13 \\
(20.6)\end{array}$ & $\begin{array}{l}26 \\
(18.8)\end{array}$ & & $1(14.3)$ & $\begin{array}{l}38 \\
(19.6)\end{array}$ & \\
\hline Very high & $5(7.9)$ & $7(5)$ & & 1 (14.3) & $11(5.5)$ & \\
\hline
\end{tabular}

Pearson's coefficient of correlation to examine the relationship between spiritual intelligence and perceived stress showed that there is an inverse correlation between total spiritual score and posttraumatic stress syndrome $(-0 / 25)$ so that with increasing spiritual intelligence, people perceived less stress and This relationship was statistically significant $(P=0 / 003)$. According to Pearson correlation coefficient test, there is a significant relationship between the total spiritual intelligence of the meaning of the components of PTSS: avoidance $(p=0.5)$, Intrusion $(p=0.014)$ and Hyper arousal $(p=0.001)$ (Table 3).

Table 3

Correlation between spiritual intelligence and post-traumatic stress syndrome and its subscales in health care workers

\begin{tabular}{|lll|}
\hline Variable & \multicolumn{2}{l|}{ Spiritual Intelligence } \\
\cline { 2 - 3 } & Coefficient & P value \\
\hline Total PTSS Score & -0.25 & 0.003 \\
Avoidance & -0.16 & 0.05 \\
\hline Intrusion & -0.2 & 0.01 \\
\hline Hyper arousal & -0.3 & 0.0001 \\
\hline
\end{tabular}

\section{Discussion}


The aim of this study was to investigate the relationship between spiritual intelligence and PTSS in staff working in Corona centers. Based on the results of the present study, $70.6 \%$ of employees with scores above 24 experienced symptoms of stress and of this $49.8 \%$ of people with a score above 33 on the IES-R score have a worrying condition for developing PTSS. According to the Wong et al study (2020), the prevalence of stress symptoms among Chinese citizens in the Covid-19 Pandemic was $8.1 \%$ (24). In the study of Huang et al (2020), the prevalence of PTSD symptoms was $27.39 \%$ among the staff of Covid-19 centers in China, in the study of Li et al. (2020) in Wuhan, China 16\%, and in the study of Zeng et al (2020), PTSD was reported 18\% (25-27). While the prevalence of mental disorders and PTSD during the prevalence of SARS was $10-11 \%(27,28)$ and during the prevalence of $\mathrm{H} 1 \mathrm{~N} 1 \mathrm{flu}$, the prevalence of PTSD among students in China was only $2 \%$ (29). However, in the study of SUN et al. (2020), the prevalence of PTSD in the medical staff was reported to be $4.4 \%$. The reason for the low percentage of the disorder can be due to a different questionnaire and a different statistical population. The PCL-C questionnaire was used and the study was performed on people from different groups of the community and the treatment staff were part of the people under study. On the other hand, the researchers in this study attributed the low prevalence to the experience of two waves of infectious disease by Chinese Mentioned in the twentieth century, so they seem to have experienced such crises, and it also seems that a study a month later the outbreak is a factor in this difference because the researchers themselves acknowledge that the prevalence of PTSS at different times In the same study it was different (15).

Perhaps one of the reasons for the high prevalence of PTSS in our study was to conduct this study on health workers working in Covid-19 centers, so that based on studies working in high-risk wards and high level of contact with patients, one of the most important reasons for the higher prevalence of PTSS and PTSD has been raised (30) and another reason can be mentioned due to the young medical and hospital staff and less work experience, so that according to studies less work experience is one of the reasons for the higher prevalence of PTSS among health care workers (31). The high prevalence of PTSD in employees can be attributed to being at the frontline of treatment and fighting the disease, the unknown of the virus and the lack of definitive treatment for it, high incidence and daily mortality, fear of infecting themselves or family members.

In this study, there was no significant relationship between any of the demographic characteristics such as age, sex, education, place of work and occupation, work experience, underlying illness in individuals or their families with the amount of stress experienced and PTSS symptoms. Although in this study, women showed more symptoms of PTSS, but these changes were not significant. In other studies, PTSD symptoms were higher in women and this could be due to the higher prevalence of risk factors such as depression and loneliness $(15,27,30,32,33)$.

In this study, there was no significant relationship between the presence of underlying diseases such as hypertension, diabetes, obesity, cardiovascular disease and autoimmunity disorder, that put people at higher risk for mortality with PTSS symptoms, but This relationship was significant in other studies, in which the study found a significant relationship between the prevalence of symptoms and the risk of disease. The reason for this difference could be due to the fact that a smaller proportion of subjects due 
to younger age, have had of underlying diseases. And another reason is that the statistical population is different so that their statistical population was different groups of society $(15,34,35)$. Although our study did not find a significant relationship between work experience and stress symptoms, other studies showed an association between work experience and perceived stress, so that studies with people with a history of more than 10 years showed more symptoms of stress. According to the researchers, this was due to the use of more experienced personnel in the pediatric ward of that hospital (27).

The average spiritual intelligence of the subjects was 124.90 and the subjects had high spiritual intelligence. There was no significant relationship between spiritual intelligence score and any of the demographic variables. In the study of Davarpanah et al (2020), Nurses working in Covid-19 ward had high spiritual intelligence and was reported as average based on Cut Off scores (36).

In other studies on nurses in Iran using the King Spiritual Intelligence Questionnaire, the spiritual intelligence score of 53(37) 61.148 (22) 48.57 (38) and based on Cut Off scores was reported as average. In Beiranvand study, more than $61 \%$ reported good spiritual intelligence score (22). This score was also reported to be moderate among nurses in Malaysia (39), but the spiritual intelligence score of $82 \%$ of nurses in China was reported to be low (40). It can be due to cultural and religious differences or different measuring instruments, and may be due to the high score in our study of different instruments or measurements at different times, so that this study was done in a pandemic situation so that based on Findings of studies of people with higher spiritual beliefs during illness or the last stages of life they had $(41-43)$.

In a study by Ramezanli et al. In patients with cancer, the average spiritual intelligence based on King spiritual intelligence tool was 97.22 and $44.5 \%$ of people had high spiritual intelligence (43). In the evaluation of spiritual intelligence in emergency response volunteers, high spiritual intelligence scores were reported (44) and Covid-19, due to the prevalence and unknowingness of the disease and high mortality, may have increased the sense of spirituality in individuals. According to the study, there was a negative relationship between spiritual intelligence and PTSS, meaning that those with higher spiritual intelligence experienced less stress. Also in the components of post-traumatic stress syndrome including avoidance, Intrusion and Hyper arousal and there was a relationship with spiritual intelligence and higher spiritual intelligence had a higher score in each of these components. The results of this study with other studies that express Religious beliefs and spiritual support reduce depression (45), increase quality of life and feel good (41).

\subsection{Conclusion}

According to the findings, PTSS is high in health care workers working in covid-19 wards and hospitals and also by increasing spiritual intelligence; the prevalence of PTSS can be reduced or brought to the desired state. As a result, by performing interventions in the field of spiritual intelligence, it is possible to control PTSS in Hospitals personnel. It is suggested that multicenter and follow-up studies be performed 
to follow the mental state of the personnel involved in the Covid-19 centers and interventions to reduce this psychological stress and PTSS symptoms in the future.

\section{Abbreviation}

World Health Organization (WHO)

Acute Respiratory Syndrome due to coronavirus type 2 (SARS-COV2)

Post-traumatic stress disorder (PTSD)

Post-traumatic stress Syndrome (PTSS)

Severe Acute Respiratory Syndrome (SARS)

Impact of Event Scale - Revised questionnaire (IES-R)

\section{Declarations}

\section{Acknowledgments}

We would like to thank the Vice Chancellor for Research of the University and all the staff of the Covid-19 Centers of Shahroud University of Medical Sciences who helped us in carrying out this research despite our busy schedule.

\section{Authors' contributions}

All authors have made a significant contribution to the planning, design, writing and reviewing processes. Analysis was conducted by S Daliry. All authors read and approved the final manuscript.

\section{Funding/Support:}

no funding for this study

\section{Availability of data and materials}

The data of this study is stored at the Shahroud university of medical science and is not publicly available for data protection reasons

\section{Ethical Approval:}


This study was approved by the Ethics Committee of Shahroud University of Medical Sciences (IR.SHMU.REC.1399.059).

\section{Consent for publication:}

Not applicable

\section{Consent to Participate:}

Full informed consent was obtained from all participants.

\section{Conflict of Interest}

The authors declare no conflict of interest.

\section{Author details:}

1. School of Public Health, Shahroud University of Medical Sciences, Shahroud, Iran.

2. Clinical Research Development Unit, Imam Hossein Hospital, Shahroud University of Medical Sciences, Shahroud, Iran.

3. School of Medicine, Shahroud University of Medical Sciences, Shahroud, Iran.

4. School of Nursing and Midwifery, Shahroud University of Medical Sciences, Shahroud, Iran.

5. School of Nursing and Midwifery, Shahroud University of Medical Sciences, Shahroud, Iran.

6. Student Research Committee, School of Paramedical Sciences, Shahroud University of Medical Sciences, Shahroud, Iran.

7. Student Research Committee, School of Paramedical Sciences, Shahroud University of Medical Sciences, Shahroud, Iran.s

\section{References}

1. WHO. 2019 novel coronavirus (2019nCoV): strategic preparedness and response plan. Feb 3 hwwiddcs-psfe. 2019 novel coronavirus (2019nCoV): strategic preparedness and response plan 2019.

2. Lai C-C, Shih T-P, Ko W-C, Tang H-J, Hsueh P-R. Severe acute respiratory syndrome coronavirus 2 (SARS-CoV-2) and coronavirus disease-2019 (COVID-19): The epidemic and the challenges. 
International Journal of Antimicrobial Agents. 2020;55(3):105924.

3. Yoo J-H. The Fight against the 2019-nCoV Outbreak: an Arduous March Has Just Begun J Korean Med Sci. 2020;35(4): 56-65.

4. WHO Coronavirus Disease (COVID-19) Dashboard 2020 [Available from:https://covid19.who.int/.

5. World Health Organization. Mental health and psychosocial considerations during the COVID-19 outbreak, 18 March 2020. World Health Organization; 2020.

6. Chan JF-W, Yuan S, Kok K-H, To KK-W, Chu H, Yang J, et al. A familial cluster of pneumonia associated with the 2019 novel coronavirus indicating person-to-person transmission: a study of a family cluster. The Lancet. 2020;395(10223):514-23.

7. Ruiz-Fernández MD, Ramos-Pichardo JD, Ibáñez-Masero O, Cabrera-Troya J, Carmona-Rega MI, Ortega-GalánÁM. Compassion fatigue, burnout, compassion satisfaction and perceived stress in healthcare professionals during the COVID-19 health crisis in Spain. Journal of clinical nursing. 2020;29(21-22):4321-30.

8. Brewin CR, Cloitre M, Hyland P, Shevlin M, Maercker A, Bryant RA, Humayun A, Jones LM, Kagee A, Rousseau C, Somasundaram D. A review of current evidence regarding the ICD-11 proposals for diagnosing PTSD and complex PTSD. Clinical psychology review. 2017 Dec 1;58:1-5.

9. Bryant RA, Creamer M, O’Donnell M, Forbes D, McFarlane AC, Silove D, Hadzi-Pavlovic D. Acute and chronic posttraumatic stress symptoms in the emergence of posttraumatic stress disorder: A network analysis. JAMA psychiatry. 2017 Feb 1;74(2):135-42.

10. Lin CY, Peng YC, Wu YH, Chang J, Chan CH, Yang DY. The psychological effect of severe acute respiratory syndrome on emergency department staff. Emergency Medicine Journal. 2007 Jan 1;24(1):12-17.

11. Perkonigg A, et al., Traumatic events and post-traumatic stress disorder in the community: prevalence, risk factors and comorbidity. Acta psychiatrica scandinavica, 2000. 101(1): p. 46-59.

12. Wu KK, Chan SK, Ma TM. Posttraumatic stress, anxiety, and depression in survivors of severe acute respiratory syndrome (SARS). Journal of Traumatic Stress: Official Publication of The International Society for Traumatic Stress Studies. 2005 Feb;18(1):39-42.

13. Wu P, Fang Y, Guan Z, Fan B, Kong J, Yao Z, Liu X, Fuller CJ, Susser E, Lu J, Hoven CW. The psychological impact of the SARS epidemic on hospital employees in China: exposure, risk perception, and altruistic acceptance of risk. The Canadian Journal of Psychiatry. 2009 May;54(5):302-11.

14. Kaseda ET, Levine AJ. Post-traumatic stress disorder: A differential diagnostic consideration for COVID-19 survivors. Clin Neuropsychol. 2020;34(7-8):1498-514.

15. Sun L, Sun Z, Wu L, Zhu Z, Zhang F, Shang Z, Jia Y, Gu J, Zhou Y, Wang Y, Liu N. Prevalence and risk factors of acute posttraumatic stress symptoms during the COVID-19 outbreak in Wuhan, China. MedRxiv. 2020 Jan 1.

16. Mohammadi MJ, Sahebalzamani M, Serajian F, Aghaineghad AA, Alavi SM, Geravandi S, Masoudzadegan M, Mohammadi Veldani A. Assessment Relationship between Spiritual Intelligence 
with Anxiety and Life Quality of Students at Tehran Medical Sciences Branch of Islamic Azad University. Educational Development of Judishapur. 2017 Sep 1;8(2):208-16.

17. Amram Y, Dryer C. The integrated spiritual intelligence scale (ISIS): Development and preliminary validation. In116th annual conference of the American Psychological Association, Boston, MA 2008 Aug 14 (14-17).

18. Sisk D. Engaging the spiritual intelligence of gifted students to build global awareness in the classroom. Roeper review. 2008;30(1):24-30.

19. Zohar D. Spiritual intelligence: The ultimate intelligence. Bloomsbury publishing; 2012 Apr 12.

20. Sahebalzamani M, Farahani H, Abasi R, Talebi M. The relationship between spiritual intelligence with psychological well-being and purpose in life of nurses. Iranian journal of nursing and midwifery research. 2013;18(1):38-41.

21. Beck JG, Grant DM, Read JP, Clapp JD, Coffey SF, Miller LM, et al. The impact of event scale-revised: psychometric properties in a sample of motor vehicle accident survivors. J Anxiety Disord. 2008;22(2):187-98.

22. beiranvand $S$, safapour $F$, zarea $S$. Assess relationship between nurses 'spiritual intelligence and selfefficacy. 3 JNE. 2019; 8 (5) :19-24. URL:http://jne.ir/article-1-1017-fa.html. (Persian)

23. Afroz GA, Hooman HA, Mahmoodi N. Considering practicality, reliability, validity finding of spiritual intelligence in students. Journal of psycholigical research fall. 2009; 1(3): 1-23.

24. Wang C, Pan R, Wan X, Tan Y, Xu L, Mclntyre RS, et al. A longitudinal study on the mental health of general population during the COVID-19 epidemic in China. Brain, Behavior, and Immunity. 2020;87:40-8.

25. Huang JZ, Han MF, Luo TD, Ren AK, Zhou XP. [Mental health survey of medical staff in a tertiary infectious disease hospital for COVID-19]. Zhonghua lao dong wei sheng zhi ye bing za zhi, Zhonghua laodong weisheng zhiyebing zazhi, Chinese journal of industrial hygiene and occupational diseases. 2020;38(3):192-5..

26. Li X, Li S, Xiang M, Fang Y, Qian K, Xu J, et al. The prevalence and risk factors of PTSD symptoms among medical assistance workers during the COVID-19 pandemic. J Psychosom Res. 2020;139:110270-.

27. Zheng R, Zhou Y, Qiu M, Yan Y, Yue J, Yu L, et al. Prevalence and associated factors of depression, anxiety, and stress among Hubei pediatric nurses during COVID-19 pandemic. Compr Psychiatry. 2021;104:152217-.

28. Chen C-S, Wu H-Y, Yang P, Yen C-F. Psychological Distress of Nurses in Taiwan Who Worked During the Outbreak of SARS. Psychiatric Services. 2005;56(1):76-9.

29. Xu J, Zheng Y, Wang M, Zhao J, Zhan Q, Fu M, et al. Predictors of symptoms of posttraumatic stress in Chinese university students during the 2009 H1N1 influenza pandemic.Med Sci Monit. 2011; 17(7): 60-64.

30. Carmassi C, Foghi C, Dell'Oste V, Cordone A, Bertelloni CA, Bui E, et al. PTSD symptoms in healthcare workers facing the three coronavirus outbreaks: What can we expect after the COVID-19 pandemic. 
Psychiatry research. 2020:113312.

31. Chan AO, Huak CY. Psychological impact of the 2003 severe acute respiratory syndrome outbreak on health care workers in a medium size regional general hospital in Singapore. Occupational Medicine. 2004;54(3):190-6.

32. Breslau N. The Epidemiology of Trauma, PTSD, and Other Posttrauma Disorders. Trauma, Violence, \& Abuse. 2009;10(3):198-210.

33. Christiansen DM, Elklit A. Sex differences in PTSD. Posttraumatic stress disorder in a global context. 2012:113-42.

34. Mazza C, Ricci E, Biondi S, Colasanti M, Ferracuti S, Napoli C, et al. A nationwide survey of psychological distress among italian people during the COVID-19 pandemic: Immediate psychological responses and associated factors. International Journal of Environmental Research and Public Health. 2020;17(9):3165.

35. Özdin S, Bayrak Özdin Ş. Levels and predictors of anxiety, depression and health anxiety during COVID-19 pandemic in Turkish society: The importance of gender. International Journal of Social Psychiatry. 2020;66(5):504-11.

36. Vahabi A, Vahabi B, Sayyad S, Moradi M, Sayyadi M. The relationship between spiritual intelligence and academic achievement among the students of Kurdistan Universities of Medical Sciences, Iran, 2016. Chronic Diseases Journal. 2021;17:9(1).

37. Riahi S, Goudarzi F, Hasanvand S, Abdollahzadeh H, Ebrahimzadeh F, Dadvari Z. Assessing the Effect of Spiritual Intelligence Training on Spiritual Care Competency in Critical Care Nurses. J Med Life. 2018;11(4):346-54.

38. Arad M, Alilu L, Habib zadeh H, Khlkhal HR, Esmhoseni G. Investigating the performance of education on nures spritual intelignce. UNMF. 2020;18(4):318-29.

39. Kaur D, Sambasivan M, Kumar N. Impact of emotional intelligence and spiritual intelligence on the caring behavior of nurses: a dimension-level exploratory study among public hospitals in Malaysia. Applied Nursing Research. 2015;28(4):293-8.

40. Yang K-P, Mao X-Y. A study of nurses' spiritual intelligence: A cross-sectional questionnaire survey. International Journal of Nursing Studies. 2007;44(6):999-1010.

41. Balboni TA, Vanderwerker LC, Block SD, Paulk ME, Lathan CS, Peteet JR, et al. Religiousness and spiritual support among advanced cancer patients and associations with end-of-life treatment preferences and quality of life. J Clin Oncol. 2007;25(5):555-60.

42. Roberts JA, Brown D, Elkins T, Larson DB. Factors influencing views of patients with gynecologic cancer about end-of-life decisions. American Journal of Obstetrics and Gynecology. 1997;176(1):166-72.

43. Ramezanli S, Jahani Z, Poorgholami F, Jahromi FF. The relationship between spiritual intelligence and happiness in cancer patients referring to selected hospitals of Tehran University of Medical Sciences. Journal of Advanced Pharmacy Education and Research. 2020;10(3):57-61. 
44. Golipour S, Haghighat S, Manavipour D. The Relationship between Spiritual and Moral Intelligence with the Meaning of Life among the Volunteers of the Emergent Reaction. The Neuroscience Journal of Shefaye Khatam. 2014 Dec 10;2(4):20-9.

45. Kristeller JL, Rhodes M, Cripe LD, Sheets V. Oncologist Assisted Spiritual Intervention Study (OASIS): patient acceptability and initial evidence of effects. The International Journal of Psychiatry in Medicine. 2005;35(4):329-47. 